\title{
Corrosion Failure of Stainless Steel Tube during Storage
} \author{
Shanjun $\mathrm{Ma}^{1, \mathrm{a}}{ }^{\text {, Shaohua } \mathrm{Li}^{1, \mathrm{~b}} \text { Lei Liang }}{ }^{2, \mathrm{c}}$ and Yang Zhao ${ }^{2}$ \\ ${ }^{1}$ School of Energy,Power and Mechanical Engineering,North China Electric Power University, \\ Beijing 102206,China \\ ${ }^{2}$ School of Energy and Mechanical Engineering, Shanghai University of Electric Power, Shanghai \\ 200090, China \\ aamashanjun@cgdc.com.cn, ${ }^{b}$ lishaohua@cdt-kxjs.com, ${ }^{c}$ lianglei@shiep.edu.cn
}

Keywords: Stainless Steel, Corrosion, Storage, EDS

Abstract. Corrosion failure of the stainless steel tube was analyzed through the methods of field investigation, chemical composition and metallographic analysis, tensile test, surface morphology and micro elements analysis. The quality accords with the standard of ASTM A688, and the stainless steel tube corrosion was due to the storage in open air environment for long term. The pitting corrosion is caused by enrichment of chloride and sulfide and may also be caused by sulfide microbial corrosion.

\section{Introduction}

Compared with copper alloy tube, stainless steel welded tube has high intensity, good dimensional accuracy, corrosion resistance, long life, low price, the total heat transfer coefficient which is not low, and a good technical and economic performance so it is widely used in heat tube of the power plant condenser and heater $[1,2]$. However, stainless steel tube is not foolproof in the manufacturing, transport, storage, installation and application process where the corrosion may happen [3]. As the tube of a nuclear power plant feed water heater, stainless steel welded tube which was manufactured by $\mathrm{F}$ company and supplied to a power station equipment manufacturers, was found corrosion pit during storage. Therefore, corrosion failure analysis was required, and the reasons of corrosion failure need to be found out.

\section{Field investigation}

The field survey found that stainless steel tube and its packaging wooden boxes have been placed outdoor for about $6 \sim 7$ months, which were experienced the rainy and hot summer. There was obvious sign of the water in the packing wooden cases which were moldy and rotten. Moldy and rotten packing cases are shown in fig. 1 .

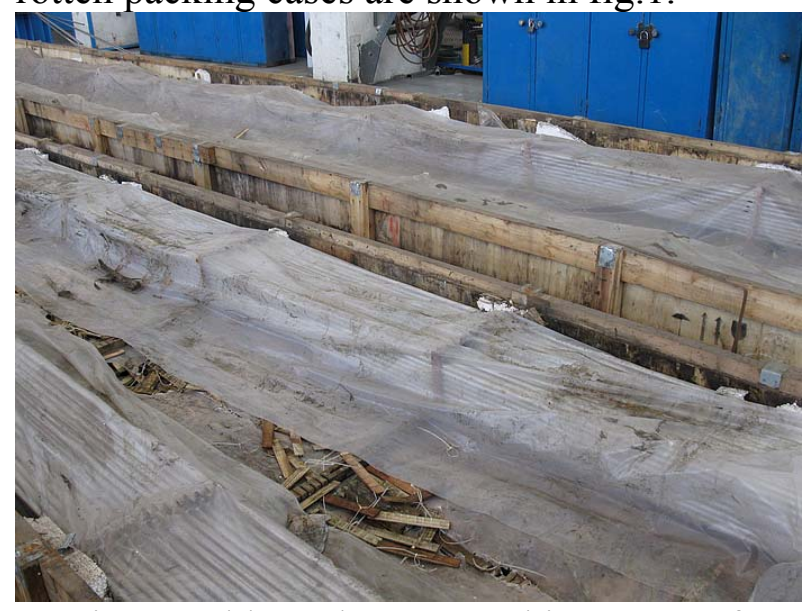

Fig.1 Moldy and rotten packing cases of stainless steel tube

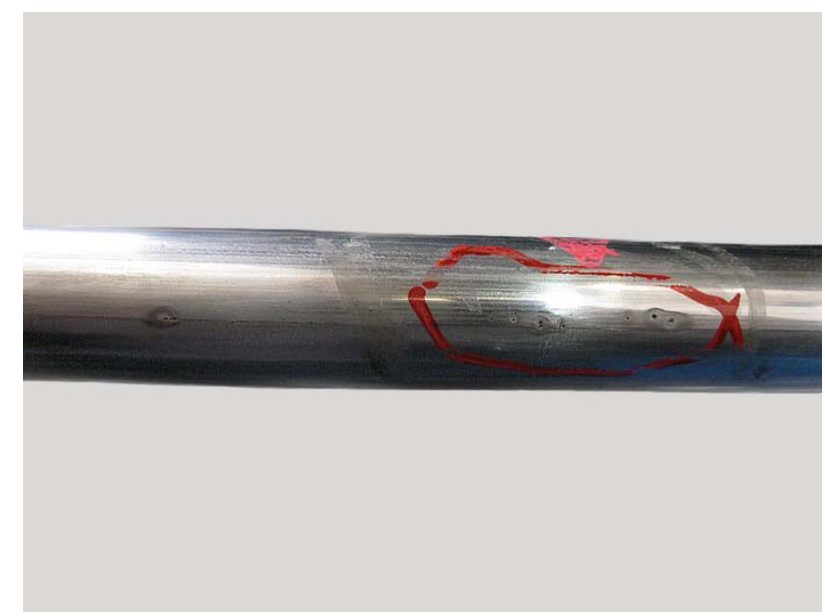

Fig.2 Corrosion pits of stainless steel tube

Some stainless steel tubes were taken out for inspection and some of them had corrosion pits. As shown in fig. 2, corrosion pits distribute randomly along the axial. Stainless steel tube material grades 
for TP304, $19 \mathrm{~mm}$ outside diameter, thickness of $0.91 \mathrm{~mm}$. The stainless steel tube specimens were taken back to laboratory for test analysis.

\section{Failure Analysis}

Through the chemical composition and metallographic analysis, tensile test, surface morphology and micro elements analysis, the reasons for corrosion failure were analyzed.

Chemical composition, metallographic analysis and tensile test. Sampling for chemical composition analysis in the specimen tube where is not corrosive, the test results are shown in table 1.

Table 1 Chemical composition test results (\%)

\begin{tabular}{ccc}
\hline Element & Specimen & $\begin{array}{c}\text { Specified value of ASTM } \\
\text { A688[4] }\end{array}$ \\
\hline $\mathrm{C}$ & 0.047 & $\leq 0.08$ \\
$\mathrm{Si}$ & 0.54 & $\leq 0.75$ \\
$\mathrm{Mn}$ & 1.09 & $\leq 2.00$ \\
$\mathrm{P}$ & 0.024 & $\leq 0.040$ \\
$\mathrm{~S}$ & 0.002 & $\leq 0.030$ \\
$\mathrm{Cr}$ & 18.12 & $18.0-20.0$ \\
$\mathrm{Ni}$ & 8.03 & $8.00-11.00$ \\
\hline
\end{tabular}

The table 1 shows that the chemical composition of stainless steel tube meets the TP304 requirements of the standard specification for welded austenitic stainless steel feedwater heater tubes.

According to the literature [5], profile specimens sampling from the area where have and not have corrosion pits of the tube were observed under a microscope after the embedding and polishing. Metallographic microstructure of corrosion specimen is shown in fig.3, and metallographic microstructure of no corrosion specimen is shown in fig.4. Fig.3 indicates that the metallographic microstructure of the specimen is austenite. In addition to the corrosion defect, matrix of metallographic microstructure itself do not see obvious flaw. Fig.4 shows that metallographic microstructure of the corrosion profile specimen is also austenite, and no obvious difference is found between the metallographic microstructure of specimen which has corrosion pits.

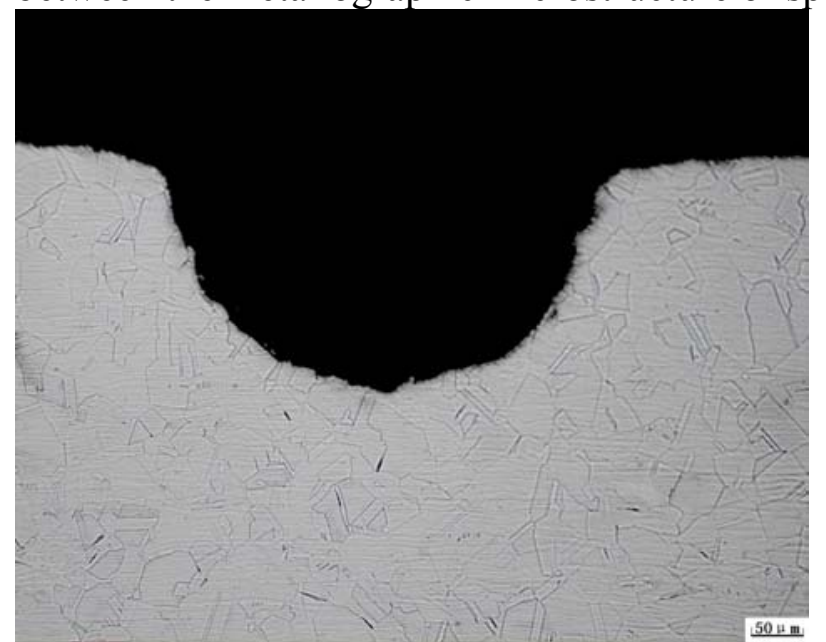

Fig.3 Metallographic microstructure of corrosion specimen

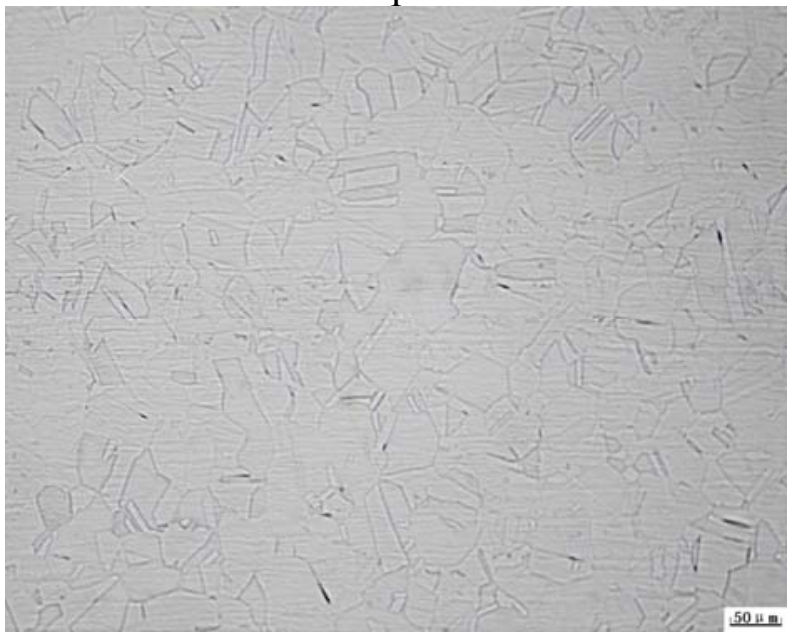

Fig.4 Metallographic microstructure of no corrosion specimen

Tensile Requirements of the stainless steel tube specimen without corrosion pit was tested on WE - 100 hydraulic universal testing machine. Yield strength, tensile strength, and elongation (in $50 \mathrm{~mm}$ ) were $310 \mathrm{MPa}, 680 \mathrm{MPa}$ and 50\%, respectively, which conforms to ASTM A688 [4] rules that greater than $205 \mathrm{MPa}, 515 \mathrm{MPa}$ and $35 \%$, respectively.

Surface morphology and micro area composition analysis. Specimens were taken from corrosion area and no obvious corrosion area and were observed in Hitachi SU-1500 scanning 
electron microscope. And EDS analysis was conducted on the specimen surface. The EDS analysis results of the no corrosion specimen which was tested after polishing reflect the chemical element of stainless steel material, and it can be used as a benchmark compared with the EDS analysis results of the corrosion specimen. EDS analysis summary data of 304 stainless steel is shown in table 2. EDS analysis diagram of the no corrosion specimen is shown in fig.5. Scanning electron microscopy (SEM) images of the no corrosion specimen is shown in fig.6. Fig.7 and fig. 8 show the analysis range and SEM image of the corrosion pit 1-1 and corrosion pit 1-2 showed in table 2.

Table 2 EDS analysis summary data of 304 stainless steel (w\%)

\begin{tabular}{ccccc}
\hline Element & $\begin{array}{c}\text { Tube no obvious } \\
\text { corrosion area }\end{array}$ & $\begin{array}{c}\text { Corrosion pit } \\
1-1\end{array}$ & $\begin{array}{c}\text { Corrosion } \\
\text { pit 1-2 }\end{array}$ & $\begin{array}{c}\text { Corrosion } \\
\text { pit 2 }\end{array}$ \\
\hline $\mathrm{C}^{*}$ & 3.08 & 14.24 & 15.64 & 16.46 \\
$\mathrm{O}$ & & 26.72 & 27.98 & 17.63 \\
$\mathrm{Si}$ & & 3.33 & 1.71 & 0.69 \\
$\mathrm{P}$ & & 0.09 & 0.18 & 0.19 \\
$\mathrm{~S}$ & & 2.23 & 3.74 & 1.56 \\
$\mathrm{Cl}$ & & 0.92 & 1.35 & 0.51 \\
$\mathrm{~K}$ & & 0.47 & 0.64 & 0.19 \\
$\mathrm{Ca}$ & & 0.55 & 0.62 & 0.27 \\
$\mathrm{Cr}$ & 19.42 & 13.66 & 16.89 & 15.06 \\
$\mathrm{Mn}$ & 1.42 & 1.04 & & \\
$\mathrm{Fe}$ & 68.56 & 33.88 & 29.21 & 43.01 \\
$\mathrm{Ni}$ & 7.53 & 2.87 & 2.04 & 4.42 \\
\hline
\end{tabular}

* The error of lighter elements such as $\mathrm{C}$ is bigger due to EDS energy analysis is half quantitative analysis.

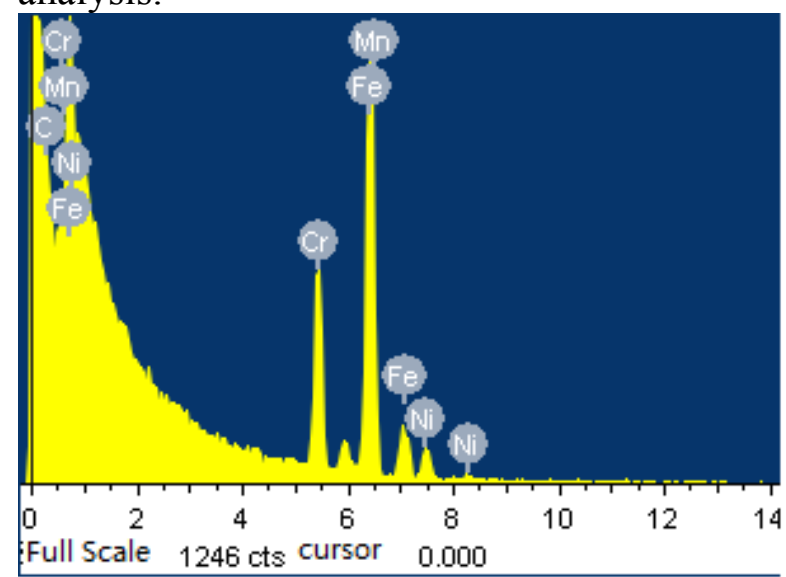

Fig.5 EDS analysis diagram of the no corrosion specimen

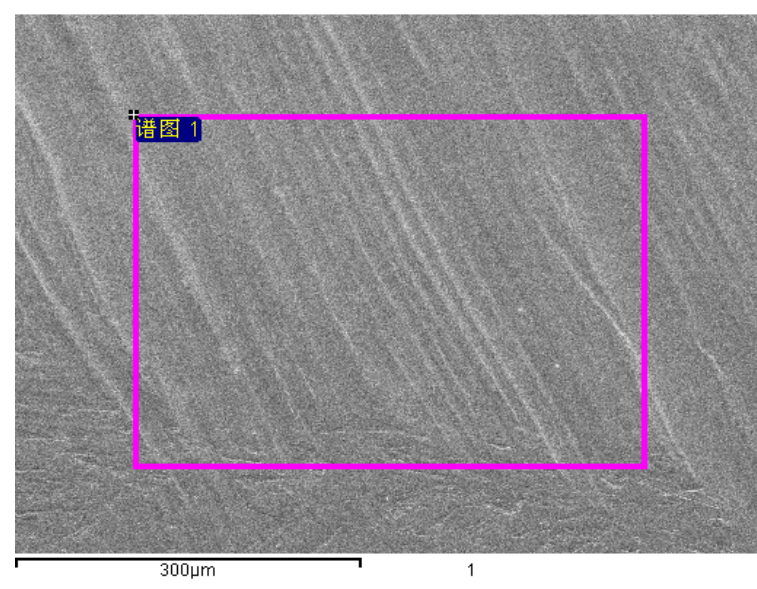

Fig.6 SEM images of the no corrosion specimen

Table 2 and fig. 5 to fig. 8 show as follows:

1. The content of the elements such as $\mathrm{Cr}, \mathrm{Ni}$ in stainless steel is consistent with the results of chemical analysis.

2. There is big difference between the elements content of stainless steel matrix and pits. In corrosion pits, there are many components which are not shown in stainless steel matrix.The components not only contain chloride, but also have a number of the $\mathrm{S}$ element. $\mathrm{Cl}$ and $\mathrm{S}$ can cause corrosion of stainless steel tube easily. In consideration of the bilging, mildewing and rotting of packaging wooden box, the existence of $\mathrm{S}$ element may also be induced by microbiologically corrosion of Sulfur. In addition, there are elements such as $\mathrm{K}$ and $\mathrm{Ca}$ which indicated salts existence. $\mathrm{O}$ element content is higher which is suggested the existence of oxide and oxygen acid salt, such as sulfate, etc.

3. The element content of different corrosion pit is different, but the difference is not obvious. The elements also have differences when EDS specimen with different range in the same corrosion pit. 
Since stainless steel tube is stored in open air for a long time, the components which are not shown in stainless steel matrix in corrosion pits are supposed to come from the environment, such as rain. Due to the insolation and rainfall, chloride and sulfide assemble in stainless steel tube surface, which cause the corrosion of the stainless steel tube.

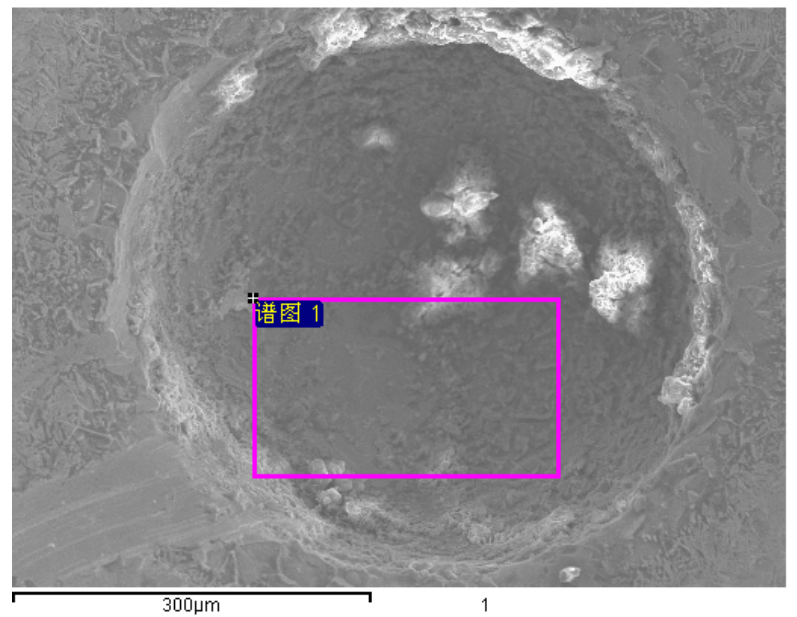

Fig.7 Analysis range and SEM image of the corrosion pit 1-1

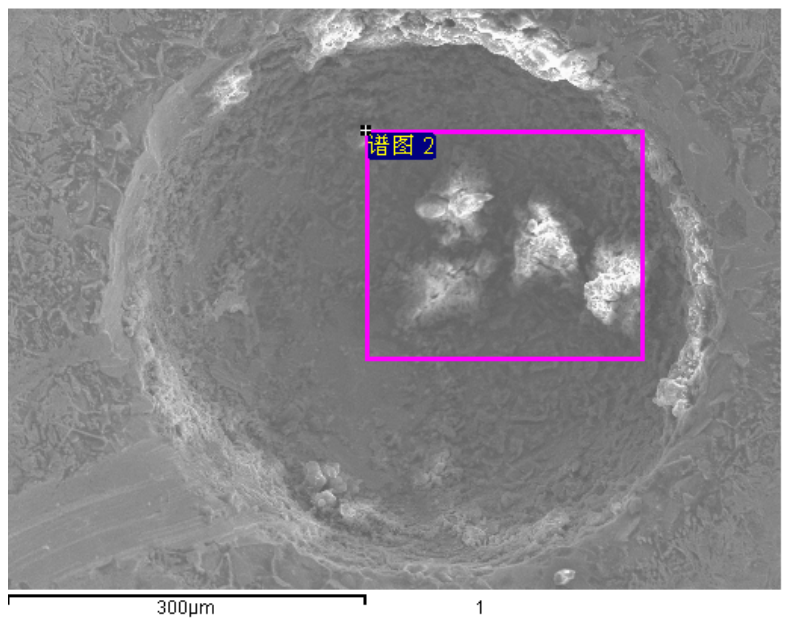

Fig.8 Analysis range and SEM image of the corrosion pit $1-2$

\section{Conclusions}

Metallographic microstructure of the specimen is austenite. Except the corrosion defect, matrix of metallographic microstructure itself does not have obvious flaw. Chemical composition and tensile properties test results of stainless steel tube accord with the standard ASTM A688. Therefore, the quality of the stainless steel tube is qualified.

Stainless steel tubes were stored in open air for a long time, and the packing wooden cases have been moldy and rotten. Chloride and sulfide are concentrated on the surface of stainless steel tube. The corrosion is caused by chloride and sulfide pitting of the outside world, and may also be caused by sulfide microbial corrosion.

\section{Acknowledgements}

This work was financially supported by the Shanghai Committee of Science and Technology (13160501000, 15DZ1200703), China.

\section{References}

[1] L. Liang, G D.Zhou, Q. Xie, et al. China Electric Power Vol.31(1998), p.37 (In Chinese)

[2] L. Liang, P. Ni, D Y. Zhang, et al. China Electric Power Vol.37(2004), p.53 (In Chinese)

[3] L. Liang, Y. Pan, J. Zhang, et al. Applied Mechanics and Materials, Vol. 448(2014), p.83

[4] ASTM A688/A688M-10. Standard Specification for Welded Austenitic Stainless Steel Feedwater Heater Tubes

[5] GB/T13298-1991. Metal microstructure test methods (In Chinese) 